\title{
BMJ Open Quality Cross-sectional study of surgical quality with a novel evidence-based tool for low-resource settings
}

\author{
Lina Roa (D ,,${ }^{1,2}$ Isabelle Citron, ${ }^{1}$ Jania A Ramos, ${ }^{1}$ Jessica Correia, ${ }^{3}$ \\ Berenice Feghali, ${ }^{3}$ Julia R Amundson, ${ }^{1}$ Saurabh Saluja, ${ }^{1}$ Nivaldo Alonso, ${ }^{4}$ \\ Rodrigo Vaz Ferreira ${ }^{3}$
}

To cite: Roa L, Citron I, Ramos JA, et al. Crosssectional study of surgical quality with a novel evidencebased tool for low-resource settings. BMJ Open Quality 2020;9:e000880. doi:10.1136/ bmjoq-2019-000880

Received 19 November 2019 Revised 14 January 2020 Accepted 7 February 2020
Check for updates

(C) Author(s) (or their employer(s)) 2020. Re-use permitted under CC BY-NC. No commercial re-use. See rights and permissions. Published by BMJ.

${ }^{1}$ Program in Global Surgery and Social Change, Department of Global Health and Social Medicine, Harvard Medical School, Boston, Massachusetts, USA

${ }^{2}$ Department of Obstetrics \& Gynecology, University of Alberta, Edmonton, Alberta, Canada

${ }^{3}$ Department of General Surgery, Universidade do Estado do Amazonas, Manaus, Amazonas, Brazil

${ }^{4}$ Department of Plastic Surgery, Universidade de Sao Paulo Hospital das Clinicas, Sao Paulo, São Paulo, Brazil

Correspondence to Dr Lina Roa;

lina_roa@hms.harvard.edu; Iroa123@gmail.com

\section{ABSTRACT}

Background Adverse events from surgical care are a major cause of death and disability, particularly in low-and-middle-income countries. Metrics for quality of surgical care developed in high-income settings are resource-intensive and inappropriate in most lower resource settings. The purpose of this study was to apply and assess the feasibility of a new tool to measure surgical quality in resource-constrained settings.

Methods This is a cross-sectional study of surgical quality using a novel evidence-based tool for quality measurement in low-resource settings. The tool was adapted for use at a tertiary hospital in Amazonas, Brazil resulting in 14 metrics of quality of care. Nine metrics were collected prospectively during a 4-week period, while five were collected retrospectively from the hospital administrative data and operating room logbooks.

Results 183 surgeries were observed, 125 patient questionnaires were administered and patient charts for 1 year were reviewed. All metrics were successfully collected. The study site met the proposed targets for timely process (7 hours from admission to surgery) and effective outcome ( $3 \%$ readmission rate). Other indicators results were equitable structure (1.1 median patient income to catchment population) and equitable outcome (2.5\% at risk of catastrophic expenditure), safe outcome (2.6\% perioperative mortality rate) and effective structure (fully qualified surgeon present $98 \%$ of cases).

Conclusion It is feasible to apply a novel surgical quality measurement tool in resource-limited settings. Prospective collection of all metrics integrated within existing hospital structures is recommended. Further applications of the tool will allow the metrics and targets to be refined and weighted to better guide surgical quality improvement measures.

\section{INTRODUCTION}

Lack of access to safe and affordable surgery and anaesthesia is a major cause of death and disability in low-and-middle-income countries (LMIC). ${ }^{1}{ }^{2}$ Currently, LMIC perform only $6.3 \%$ of the world's surgical procedures and experience two-thirds of adverse healthcare events and $50 \%$ of postoperative mortality. ${ }^{1-3}$ The importance of improved access to high-quality surgical care worldwide has been recognised. The World Bank has set four World Development Indicators (WDI) and targets to improve access to safe and affordable surgical care. To achieve the target of 5000 surgical procedures per 100 000 people by 2030, 143 million additional surgical procedures are required annually. ${ }^{2}$ As efforts to scale up surgical volume continue, efforts to attain high levels of surgical quality of care are essential to avoid needless harm.

Quality of care is complex to characterise and there are two widely accepted definitions. First, that of Institute of Medicine (IOM) which defines high quality of care as being safe, effective, timely, patient-centred, efficient and equitable. ${ }^{4}$ Second, that of Donabedian which refers to high-quality care as having high-quality structures, processes and outcomes. ${ }^{56}$ Given these multiple facets, quality of care is challenging to measure but the ability to do so is imperative for improvement. A recent systematic review of research on surgical quality in LMIC shows that research has focused on single outcomes such as mortality and surgical site infections with minimal efforts to standardise metrics or to comprehensively evaluate multiple aspects of quality of care or quality of health systems. ${ }^{7}$ Current tools for measuring surgical quality have mostly been developed in high-income countries, often require long-term patient follow-up and advanced health information systems and are resource-intensive. ${ }^{8-11}$ These tools are often neither relevant nor feasible to implement in low-resource settings. To overcome these challenges, a quality tool was developed specifically for low-resource settings with a set of evidence-based indicators spanning all domains of high-quality care: safety, effectiveness, patient-centredness, timeliness, efficiency and equity while using Donabedian's framework of structure, process and outcomes. ${ }^{12}$ Unlike other tools, the metrics are based on single inpatient encounters and use data collection tools that represent simple 
modifications to data registries already in use in most lowresource settings. ${ }^{12}$ The theoretical framework has been developed but this tool has not yet been implemented.

Brazil is an upper middle-income country comprised of five regions which are further subdivided into 26 states and a federal district. It has a national health system (Sistema Unico de Saúde (SUS)) which provides universal, free at point-of-care services, with $28 \%$ of the population having supplemental private insurance plans. ${ }^{13}$ At the national level, Brazil meets benchmark targets for the surgical WDI, but there are large regional inequalities consistent with the country's health and economic disparities. $^{1415}$

To improve quality of surgical care in low-resource settings, we must first improve the ability to measure it. Thus, the aim of this study was to measure surgical quality and assess feasibility of a novel surgical quality tool for low resource settings in the state of Amazonas, Brazil.

\section{METHODS}

This is a cross-sectional study in which prospective data on emergency and elective abdominal surgery cases and retrospective data on all surgical cases were collected at Hospital e Pronto-Socorro 28 de Agosto, a tertiary trauma hospital in Manaus, State of Amazonas, Brazil. Abdominal surgeries were selected for prospective observation as they affect a cross section of the population and consistently require timely surgical care. These data were used to calculate the 14 indicators of surgical quality. Prospective data were collected from 24 July to 21 August 2017 and retrospective data spanned from January 2017 to January 2018.

\section{Instrument}

The quality tool implemented, adapted from Citron et $a l,{ }^{12}$ consists of 14 evidence-based metrics that integrate the three Donabedian framework dimensions: structure, process and outcomes, with the six IOM dimensions for high-quality care: safe, effective, patient-centred, timely, efficient and equitable ${ }^{16}$ (online supplementary appendix).

The tool was adapted to the local site with the following modifications. Caesarean section rate, an effective outcome measure, was replaced by readmission rate as the study site does not provide obstetric care and sufficient evidence exists as to the validity of this measure. ${ }^{17} 18$ Provider density, a measure of effective structure, was replaced by proportion of surgeries with a fully qualified surgeon present as the hospital providers are employed as a pool and it was not possible to establish the full-time equivalents. A fully qualified surgeon was defined as a physician who had completed surgical residency training. It was recognised that prospective collection of perioperative mortality rate (POMR) and Clavien-Dindo classification of complications would not be possible, therefore only non-risk-adjusted POMR was collected retrospectively from hospital records. The remaining indicators were employed as originally designed (table 1).

\section{Data Collection}

Retrospective and prospective data collection was performed using the four data collection tools: hospital administrative data, ${ }^{12}$ modified operating room (OR) logbook, ${ }^{12}$ modified intraoperative checklist and patient discharge survey ${ }^{12} 1920$ (online supplementary appendix). The data collection method, metric, definition, domain and proposed targets for each indicator are shown in table 2.

\section{Prospective data collection}

Prospective data collection was performed using a modified intraoperative checklist and a patient survey at the time of discharge (online supplementary appendix).

Table 1 Modified surgical care quality tool implemented in this study

\begin{tabular}{|c|c|c|c|c|c|c|c|}
\hline & & \multicolumn{6}{|c|}{ Institute Of Medicine measures } \\
\hline & & Safe & Effective & Patient-centred & Timely & Efficient & Equitable \\
\hline \multirow{3}{*}{$\begin{array}{l}\text { Donabedian } \\
\text { framework }\end{array}$} & Structure & $\begin{array}{l}\text { Morbidity } \\
\text { and } \\
\text { mortality } \\
\text { conference }\end{array}$ & $\begin{array}{l}\text { Attending } \\
\text { surgeon present } \\
\text { (proxy for } \\
\text { provider density) }\end{array}$ & - & $\begin{array}{l}\text { Travel time to } \\
\text { hospital }\end{array}$ & - & $\begin{array}{l}\text { Patient median } \\
\text { income to } \\
\text { catchment } \\
\text { population }\end{array}$ \\
\hline & Process & $\begin{array}{l}\text { Safe surgery } \\
\text { checklist } \\
\text { use }\end{array}$ & $\begin{array}{l}\text { Procedure } \\
\text { density }\end{array}$ & Use of consent & $\begin{array}{l}\text { Time from } \\
\text { ED arrival to } \\
\text { non-elective } \\
\text { abdominal } \\
\text { surgery }\end{array}$ & $\begin{array}{l}\text { Daily OR } \\
\text { usage }\end{array}$ & - \\
\hline & Outcome & POMR & $\begin{array}{l}\text { Readmission } \\
\text { rates within } 30 \\
\text { days (proxy } \\
\text { for caesarean } \\
\text { section rate) }\end{array}$ & $\begin{array}{l}\text { Patient hospital } \\
\text { satisfaction } \\
\text { questionnaire }\end{array}$ & Follow-up plan & - & $\begin{array}{l}\text { Catastrophic } \\
\text { patient-reported } \\
\text { expenditure }\end{array}$ \\
\hline
\end{tabular}

ED, emergency department; IOM, Institute of Medicine; OR, operating room; POMR, perioperative mortality rate. 
Table 2 Indicator definitions, data collection methods and proposed targets

\begin{tabular}{|c|c|c|c|c|}
\hline Measure & $\begin{array}{l}\text { Domain } \\
\text { covered }\end{array}$ & Data collection & Definition & Target \\
\hline \multicolumn{5}{|c|}{ Data source: Hospital administrative data } \\
\hline POMR & Safe outcome & $\begin{array}{l}\text { Retrospective } \\
\text { from patient } \\
\text { charts }\end{array}$ & $\begin{array}{l}\text { Total number of inhospital deaths of patients who } \\
\text { underwent a surgical procedure during the same } \\
\text { admission over the total number of surgical procedures } \\
\text { performed in the same time period }\end{array}$ & $1 \%-2 \%$ \\
\hline $\begin{array}{l}\text { Readmission rate within } 30 \\
\text { days }\end{array}$ & $\begin{array}{l}\text { Effective } \\
\text { outcome }\end{array}$ & $\begin{array}{l}\text { Retrospective } \\
\text { from patient } \\
\text { charts }\end{array}$ & $\begin{array}{l}\text { Percentage of patients who had a readmission to the } \\
\text { study site within } 30 \text { days of their surgery }\end{array}$ & $<10 \%$ \\
\hline \multicolumn{5}{|l|}{ Data source: OR logbook } \\
\hline Procedure density & Effective process & Retrospective & $\begin{array}{l}\text { Number of surgical cases performed in the OR/ } \\
\text { population of catchment area } 100000\end{array}$ & $\begin{array}{l}5000 \text { cases } / 100 \\
000 \text { population }\end{array}$ \\
\hline
\end{tabular}

Data source: Modified intraoperative checklist delivered by researcher

\begin{tabular}{|c|c|c|c|c|}
\hline Safe surgery checklist use & Safe process & Prospective & $\begin{array}{l}\text { Proportion of surgical cases performed in the OR as } \\
\text { per full WHO safe surgery checklist. Specific use of } \\
\text { pulse oximetry, patient name band and intraoperative } \\
\text { antibiotics }\end{array}$ & $100 \%$ \\
\hline Fully qualified surgeon present & $\begin{array}{l}\text { Effective } \\
\text { structure }\end{array}$ & Prospective & $\begin{array}{l}\text { Per cent of surgeries performed with an attending } \\
\text { surgeon present }\end{array}$ & $100 \%$ \\
\hline \multicolumn{5}{|c|}{ Data source: Patient discharge survey delivered by researcher } \\
\hline $\begin{array}{l}\text { Patient hospital satisfaction } \\
\text { questionnaire }\end{array}$ & $\begin{array}{l}\text { Patient-centred } \\
\text { outcome }\end{array}$ & Prospective & Mean total score on HCAHPS survey & $\begin{array}{l}\text { 'Top box } \\
\text { response rate' } \\
70 \% \text { across all } \\
\text { fields }\end{array}$ \\
\hline Follow-up plan & Timely outcome & Prospective & $\begin{array}{l}\text { Proportion of patients answering yes to 'Have you } \\
\text { received instructions on how you will receive continuing } \\
\text { care?' }\end{array}$ & $100 \%$ \\
\hline $\begin{array}{l}\text { Mean income compared with } \\
\text { mean catchment income (or } \\
\text { GDP/capita) }\end{array}$ & $\begin{array}{l}\text { Equitable } \\
\text { structure }\end{array}$ & Prospective & $\begin{array}{l}\text { Mean income determined on patient exit interview/mean } \\
\text { income of catchment population or GDP per capita }\end{array}$ & $\leq 1$ \\
\hline $\begin{array}{l}\text { Proportion of patients } \\
\text { experiencing catastrophic } \\
\text { expenditure }\end{array}$ & $\begin{array}{l}\text { Equitable } \\
\text { outcome }\end{array}$ & Prospective & $\begin{array}{l}\text { Proportion of patients where sum of total self-reported } \\
\text { expenditure/self-reported income is }>40 \%\end{array}$ & $0 \%$ \\
\hline
\end{tabular}

ED, emergency department; GDP, gross domestic product; HCAHPS, Hospital Consumer Assessment of Healthcare Providers and Systems; OR, operating room; POMR, perioperative mortality rate.

Data collection took place during a 4-week period from 24 July to 21 August 2017 with at least one data collector present 24 hours a day. Our study population was determined to be all the patients undergoing abdominal surgery during this period, as it was determined 1 month would be sufficient time to determine feasibility of the tool. All consecutive cases during the data collection period were included to avoid potential sources of bias in cases observed. The modified intraoperative checklist was used during all cases during the study period. The survey was administered in Portuguese on the day of discharge following any abdominal surgery which involved an inpatient stay. All data were recorded electronically using Kobo Toolbox. ${ }^{21}$ 


\section{Retrospective data}

Retrospective data collection of hospital baseline administrative data and OR logbook data from January 2017 to January 2018 was performed to obtain five of the indicators: safe structure, safe outcome, effective process, effective outcome and efficient process (table 2).

\section{Hospital administrative data}

Five variables were collected retrospectively. Data on the number of morbidity and mortality conferences and surgical volume data were collected for 1-year period while POMR data were collected for a 6-month period. Data on readmission rate within 30 days of surgical procedure and OR utilisation were estimated during a 4-week period. For variables requiring a value per 100000 population the hospital catchment area was defined as one-fourth of the population of Amazonas, as the study hospital is one of the four hospitals which serves as a referral centre for the state and currently no consensus on defined catchment area exists in the region.

Catastrophic expenditure was estimated using patient's reported income and direct and indirect expenditures. The state of Amazonas income was obtained as the total income from all sources from the Brazilian Institute of Geography and Statistics data for the year of $2017 .^{22}$ Purchase power parity was used to convert Brazilian Reals to 2017 US\$. ${ }^{23}$

\section{Data analysis}

Descriptive statistics were calculated for the indicators as appropriate. For discrete data we present ratios or percentages, and for continuous data mean and SD or median and IQR. If a data point was missing, that patient was excluded only for the quality indicator calculation for which the missing data point was needed. The indicator for patient-centred outcome, patient hospital satisfaction, was calculated as the proportion of patients giving the highest rated option for responses using the Hospital Consumer Assessment of Healthcare Providers and Systems scoring methodology. ${ }^{24}$

Subgroup analysis comparing emergency and elective cases was performed for three of the indicators: safe process (WHO safe surgery checklist use and its specific components of pulse oximetry, name band and antibiotics), patient-centred outcome (patient satisfaction) and timely outcome (follow-up plan at the time of discharge). A two-tailed t-test was conducted and an alpha of $\mathrm{p}<0.05$ was used to determine statistical significance. All statistical analyses were performed using Microsoft Excel V.16.4 and Stata V.15.0 (StataCorp).

\section{Patient and public involvement}

Patients and the general public were not involved in the development of the research question.

\section{RESULTS}

In the year 2017, a total of 7214 surgeries were performed across all specialties. During the 4 -week prospective data collection period, 207 abdominal surgeries were performed and 183 were observed during this study. A total of 125 patients gave consent to complete the discharge survey. Demographic characteristics of patients are shown in table 3 .

\section{Indicators}

Fourteen indicators from the modified surgical quality tool were successfully collected. The hospital met the targets for effective outcome and timely process domain. The rest of the indicators were not met. This included safe structure, process and outcome, effective structure and process, patient-centred process and outcome, timely structure and outcome and equitable structure and outcome (table 4).

\section{Safe care indicators}

There were no morbidity and mortality conferences held at the hospital. The safe surgery checklist in its entirety was not used in any of the surgeries observed. In terms of the specific components patient name band was not used in any of the surgeries, while pulse oximetry was used for $100 \%$ of patients. Perioperative antibiotics were administered in $69 \%(124 / 181)$ of cases, with higher administration in emergency cases at $79 \%(108 / 144)$ than in elective cases at $43 \%(16 / 37)(\mathrm{p}<0.05)$. POMR was estimated at $2.6 \%(86 / 3249)$ over a 6 -month period. In the original tool, risk adjustment data on functional status, American Society of Anesthesiologists' physical status classification system or wound type are prospectively collected, however in this study POMR data were retrospectively collected and risk adjustment data were not available. The only exception was re-operating rate estimated to be $6.7 \%(13 / 195)$ for the 4 -week period of prospective data collection.

\section{Effective care indicators}

Procedure density for 2017 was 710 per 100000 catchment population. Of the 207 patients who underwent surgery during the prospective period, we were unable to track nine patients during the 30-day postoperative period and three patients were reported as dead. Of the remaining 195 patients, 3\% (5/195) were readmitted within 30 days of their first surgery at the study site. Of the 183 abdominal surgeries observed, 98\% (179/183) of all surgeries were performed with a fully qualified surgeon present, with the remaining ones performed by a surgical resident.

\section{Patient-centred care indicators}

Written consent was obtained in $74 \%$ (134/182) of surgeries, with $92 \%(34 / 37)$ of elective cases having consent documentation but only $69 \%$ (100/145) of emergency cases $(p<0.05)$. For the patient hospital satisfaction questionnaire, on average only 3 of the 10 categories received a top box response rate of greater than $70 \%$ (table 5). However, in elective cases, six categories received a top box response rate greater than $70 \%$ compared with only three categories for emergency cases. 
Table 3 Demographics of observed surgeries and of discharge survey respondents

\begin{tabular}{|c|c|c|c|c|c|}
\hline \multicolumn{3}{|c|}{ Abdominal surgeries demographics } & \multicolumn{3}{|c|}{ Discharge surveys demographics } \\
\hline Surgery type & & $\mathrm{N}(\%)$ & Surgery type & & $\mathrm{N}(\%)$ \\
\hline & Emergency & $146(80 \%)$ & & Emergency & $99(79 \%)$ \\
\hline & Elective & $37(20 \%)$ & & Elective & $26(21 \%)$ \\
\hline & Total & 183 & & Total & 125 \\
\hline \multirow[t]{19}{*}{ Procedure type } & & $N(\%)$ & Gender & & $N(\%)$ \\
\hline & Appendectomy & $62(34 \%)$ & & Female & $61(49 \%)$ \\
\hline & $\begin{array}{l}\text { Exploratory } \\
\text { Laparotomy }\end{array}$ & $52(28 \%)$ & & Male & $64(51 \%)$ \\
\hline & Cholecystectomy & $39(21 \%)$ & Age & & \\
\hline & Hernia repair & $11(6 \%)$ & & Mean (SD) & $40(16.8)$ \\
\hline & Other & $10(5 \%)$ & Education & & $\mathrm{N}(\%)$ \\
\hline & $\begin{array}{l}\text { Repeat Exploratory } \\
\text { Laparotomy }\end{array}$ & $9(5 \%)$ & & 8th grade or less & $45(36 \%)$ \\
\hline & & & & High school, no diploma & $14(11 \%)$ \\
\hline & & & & High school, graduate & $47(38 \%)$ \\
\hline & & & & University courses & $19(15 \%)$ \\
\hline & & & Annual income & & $N(\%)$ \\
\hline & & & & $<12000$ BR (US\$5833) & $31(26 \%)$ \\
\hline & & & & $\begin{array}{l}12 \text { 000-240 } 000 \text { (US\$5833- } \\
\text { US } \$ 11667)\end{array}$ & $50(42 \%)$ \\
\hline & & & & $\begin{array}{l}24000-60000 \text { (US\$11 667- } \\
\text { US\$29 169) }\end{array}$ & $23(19 \%)$ \\
\hline & & & & $>60000$ (US\$29 169) & $14(12 \%)$ \\
\hline & & & Survey section $\mathrm{r}$ & onse rates & $\mathrm{N}(\%)$ \\
\hline & & & & HCAHPS & $125(100 \%)$ \\
\hline & & & & Income and expenses & $118(94 \%)$ \\
\hline & & & & Delays of care & $104(83 \%)$ \\
\hline
\end{tabular}

HCAHPS, Hospital Consumer Assessment of Healthcare Providers and Systems.

Table 4 Surgical care quality tool targets and results

\begin{tabular}{|c|c|c|c|c|c|c|c|}
\hline & & \multicolumn{6}{|l|}{ IOM measures } \\
\hline & & Safe & Effective & Patient-centred & Timely & Efficient & Equitable \\
\hline \multirow[t]{2}{*}{$\begin{array}{l}\text { Donabedian } \\
\text { framework }\end{array}$} & Structure & $\begin{array}{l}\text { Morbidity } \\
\text { and mortality } \\
\text { conference } \\
0 \\
\text { (minimum } 9 \text { per } \\
\text { year) }\end{array}$ & $\begin{array}{l}\text { Attending } \\
\text { surgeon present } \\
98 \% \\
(100 \%)\end{array}$ & - & $\begin{array}{l}\text { Travel time to hospital } \\
31 \%<2 \text { hours } \\
\text { (80\%<2 hours) }\end{array}$ & - & $\begin{array}{l}\text { Patient median } \\
\text { income to catchment } \\
\text { population } \\
\mathbf{1 . 1} \\
(\leq 1)\end{array}$ \\
\hline & Outcome & $\begin{array}{l}\text { POMR } \\
2.6 \% \\
(1-2 \%)\end{array}$ & $\begin{array}{l}\text { Readmission } \\
\text { rates within } 30 \\
\text { days } \\
\mathbf{3} \% \\
(<10 \%)\end{array}$ & $\begin{array}{l}\text { Patient hospital } \\
\text { satisfaction } \\
\text { questionnaire } \\
70 \% \text { in } 3 / 10 \text { fields } \\
\text { (70\% across all } \\
\text { fields) }\end{array}$ & $\begin{array}{l}\text { Follow-up plan } \\
\mathbf{4 7 \%} \\
(100 \%)\end{array}$ & - & $\begin{array}{l}\text { Catastrophic patient- } \\
\text { reported expenditure } \\
2.5 \% \\
(0 \%)\end{array}$ \\
\hline
\end{tabular}

Green highlights the indicators for which set targets were met. Red indicates the targets that were not met.

ED, Emergency Department; ED, emergency department; IOM, Institute of Medicine; OR, operating room; POMR, perioperative mortality rate. 
Table 5 HCAHPS questionnaire average per cent top box score results by category

\begin{tabular}{llll}
\hline & Overall (\%) (n=125) & Elective (\%) (n=26) & Emergency (\%) (n=99) \\
\hline Communication with nurses (Q1-3) & 86 & 94 & 84 \\
Communication with doctors (Q5-7) & 85 & 96 & 82 \\
\hline Responsiveness hospital staff (Q4,11) & 34 & 30 & 33 \\
Pain management (Q13,14) & 80 & 77 & 81 \\
Communication about medicines (Q16,17) & 57 & 35 & 61 \\
Discharge information (Q19,20) & 34 & 82 & 21 \\
Cleanliness of hospital (Q8) & 21 & 31 & 18 \\
Quietness of hospital (Q9) & 58 & 77 & 53 \\
Hospital rating (Q21) & 61 & 77 & 57 \\
Recommend the hospital (Q22) & 55 & 62 & 54 \\
\hline
\end{tabular}

Highlighted are the targets met with scores $>70 \%$.

HCAHPS, Hospital Consumer Assessment of Healthcare Providers and Systems.

Overall, hospital cleanliness was the worst scoring category, and communication with doctors and nurses the best scoring.

\section{Timely care indicators}

Of the 104 responses related to timing of care in the discharge questionnaire, $84 \% \quad(87 / 104)$ were emergency cases and $16 \%(17 / 104)$ were elective. In emergency cases, the median time for patients to seek care was 8 hours $(\mathrm{IQR}=20.8)$, ranging from immediately after perceiving symptoms to 2 months (figure 1). Overall, only $31 \%(32 / 104)$ of the patients took less than 2 hours to travel to the hospital, with the median travel time of 4.2 hours ( $\mathrm{IQR}=23.0)$. When looking at emergency cases specifically, $28 \%(24 / 87)$ of patients reached the hospital within 2 hours, with median travel time of 4.4 hours ( $\mathrm{IQR}=23.3)$. On arrival, of the emergency abdominal surgeries observed, $79 \%(110 / 139)$ of cases had their surgery within 24 hours of arrival to the hospital, with the median time from arrival to surgery of 7 hours $(\mathrm{IQR}=8.1)$. The three delays in accessing care, commonly defined in the literature, ${ }^{19}$ were mapped for patients undergoing emergency abdominal surgery (figure 1)

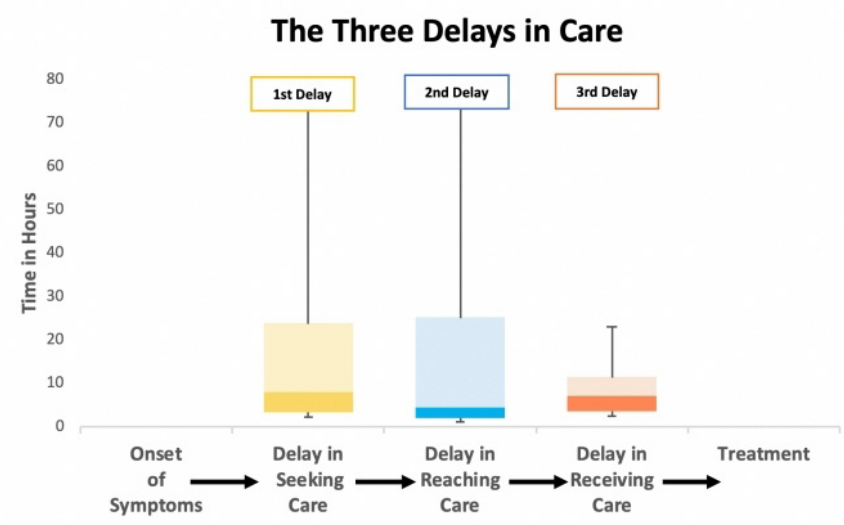

Figure 1 The three delays of care in the patient's journey for emergency abdominal surgery.
Forty-seven per cent $(59 / 125)$ of patients had a follow-up plan at discharge, with $81 \%(21 / 26)$ of the elective cases having a follow-up plan, but only $38 \%$ (38/99) of the emergency cases.

\section{Efficient care indicators}

Over the 4 weeks of prospective study observation, for all surgeries performed in the hospital, the mean daily OR utilisation was $45.1 \%$ (SD 6.35).

\section{Equitable care indicators}

The annual average patient-reported income was US $\$ 12$ 455 (25 $621 \mathrm{BRL}$ ) ( $\mathrm{SD}=8077$ ). The average annual salary of Amazonas is US\$11 189 (23 016 BRL) resulting in a 1.1 ratio for the patient average annual income to the catchment population. Of the 118 patients, only $2(2.54 \%)$ reported expenses that exceeded $40 \%$ of their annual income, corresponding to catastrophic expenditure.

\section{DISCUSSION}

This is the first study to comprehensively measure quality of surgical care using a novel tool specifically designed for resource-limited settings. Due to foreseen challenges, the tool required adaptation for use in this particular hospital by replacing two indicators and collecting five indicators retrospectively. As a result of the tool adaptation, all 14 indicators were successfully collected and provided the hospital with insight on specific strengths and particular areas for quality improvement.

Previous studies addressing quality of surgical care in LMICs have largely focused on individual measures, mostly mortality and morbidity, with few taking a comprehensive approach to quality. ${ }^{725-27}$ The tool employed in this study combines many of these individual measures and systematically captures all facets of surgical quality, including structures, processes and outcomes. In Brazil, prior studies have shown that the WHO safe surgery checklist is not routinely employed and that delay in receiving surgical care is a major factor in patient mortality. ${ }^{2527}$ The 
findings of this study support minimal implementation of the full WHO safe surgery checklist but they characterised compliance with specific items of the checklist and found differences between emergency and elective procedures. Our findings on timely care indicators are consistent with the literature in Brazil but the novel quality tool goes beyond measuring access to care and facilitates characterisation of the three delays in accessing care, providing useful information on when interventions to increase timely care would be the most beneficial. Previous studies had shown poor satisfaction with SUS medical care in Brazil, particularly with surgical care. ${ }^{28}$ This is supported by our findings on the patient-centred outcome of satisfaction which showed $70 \%$ of patients were satisfied in only 3 of 10 categories.

In comparison with other tools available and commonly used in high-income settings, this novel tool required few resources, covered a single inpatient encounter and used existing data, which contributed to making data collection feasible. The authors opted to have direct external observers to complete the prospective data collection and administer discharge questionnaire. This was to assess the feasibility of using the surgical quality tool for data collection, without confounding our results with challenges inherent in implementation. Implementation of the tool into everyday data collection will be an important next step. Additionally, POMR, readmission data and return to the OR data were collected retrospectively which was time-consuming. For the tool to be applicable and sustainable, the processes carried out by the external observers would need to be integrated into everyday practice by the facility staff, mainly through the adoption of modified data registries. Currently, efforts for the indicator collection tools to be integrated into routine hospital practice are underway.

In addition to quality, the tool can be used to evaluate surgical care access as it incorporates the surgical WDI indicators. Our study indicated that only $32 \%$ of patients accessed a facility providing surgical care within 2-hour access compared with the modelled regional estimate of $97.2 \%$ of the population being within 2 hours of surgical care, conversely $97.5 \%$ of patients in our study had protection from catastrophic expenditures compared with the modelled regional average of $82 \% .{ }^{14}$ The study by Massenburg et al used modelled estimates of access compared with the direct patient reports in this study, likely making this study more accurate. The estimated POMR of $2.6 \%$ was higher than the previous estimate of $1.12 \%$ for the North Region obtained from national databases and the target of $<1 \%$. This is likely due to the study site being a tertiary centre with more complex cases and a hospital that does not perform caesarean sections, a common surgical procedure that has a low mortality rate. The differences in estimates between our studies and previously reported data highlight the importance of hospital-based indicators to provide meaningful data that can be used to guide quality improvement.
And yet, by employing this tool widely, regional and national, collection of the six surgical WDI can be achieved.

\section{Limitations and future directions}

Our study was limited by the absence of a predefined catchment population for the study hospital which was required to calculate two of the indicators, procedure density and patient median income to catchment population. We defined the catchment area as one-fourth of the population of Amazonas, based on the number of hospitals in the state, which might be an overestimate of the true catchment area of the hospital. However, local providers experience is that most surgical cases are brought to the study site, highlighting the uncertainty when estimating the catchment area. Given the specialist nature of the hospital, targets for procedure density were not applicable as a number of procedure types, for example caesarians or elective orthopaedic surgery are not undertaken at the site. Similarly, the equitable structure indicator requires the catchment population income, instead GDP per capita in the state was used as proxy. Predefined catchment areas or refining of the indicators could facilitate implementation of the surgical tool. The readmission rate and POMR indicators were collected only at the study facility and patients who sought care at a different facility were likely missed. Furthermore, despite the quality tool being designed for prospective collection, five of the indicators had to be collected retrospectively. The retrospective collection was laborious, and for quality measurement to be a continuous sustainable endeavour we highly recommend prospective data collection for all the indicators by integrating these metrics as part of the hospital information system.

This study demonstrated that it is feasible to adapt the surgical quality framework to the local context and comprehensively measure surgical quality, suggesting that the tool could be used in other low-resource settings. In addition to local quality improvement, the widespread use of this tool would allow for comparison between facilities within a region, and regions within the country in order to guide the efficient allocation of limited resources and support facilities to provide high-quality care. For ease of comparison, the indicators in the tool should be combined into a composite score with indicators weighted according to importance. Although all measures in the tool are required in high-quality surgical systems, some indicators such as patient mortality, morbidity satisfaction and catastrophic expenditures are indivisible from highquality care, therefore they may require greater weighting than other factors such as a patient having follow-up plan at the time of discharge. In order to be able to assign meaningful weights to each item to create a composite score that measures all aspect of surgical care, and not a single indicator, a significantly larger body of data from the tool is required. 


\section{CONCLUSION}

As access to surgical care is scaled up worldwide, robust tools to track surgical quality and guide quality improvement at the facility, regional and national levels will be essential to ensure universal access to high-quality surgical care. This study demonstrates that it is feasible to comprehensively measure surgical quality in low-resource settings. Integration of prospective systems of data collection into routine practice is required to make this data collection sustainable.

Acknowledgements We would like to acknowledge the dedication and contribution of the following data collectors: Nicolas Babilônia Cavalcanti, Gabriele Silva Marinho, Yasmin Bastos Silva Gomes, Nayra da Silva Freitas, Marcela Catunda de Souza Michiles and Thais Gomes Oliveira. This work would not have been possible without them.

Contributors IC, JRA, JC, SS and RVF contributed to study design. JAR, JC and BF contributed with data collection and patient recruitment. LR, IC and JAR contributed with data analysis and interpretation. LR, IC and JAR drafted the initial draft. All authors significantly reviewed the manuscript. LR, NA and RVF contributed with overall supervision and resources.

Funding The authors have not declared a specific grant for this research from any funding agency in the public, commercial or not-for-profit sectors.

Competing interests LR, IC and JAR received generous support from the Ronda Stryker and William Johnston Global Surgery Fellowship Fund. None of the authors declare any conflict of interest.

Patient consent for publication Not required.

Ethics approval This study was approved by the ethics committee of Universidade do Estado do Amazonas and granted IRB exemption from Boston Children's Hospital.

Provenance and peer review Not commissioned; externally peer reviewed.

Data availability statement Data are available upon reasonable request. Data consisting of deidentified participant data is available on request to Iroa123@gmail. com.

Open access This is an open access article distributed in accordance with the Creative Commons Attribution Non Commercial (CC BY-NC 4.0) license, which permits others to distribute, remix, adapt, build upon this work non-commercially, and license their derivative works on different terms, provided the original work is properly cited, appropriate credit is given, any changes made indicated, and the use is non-commercial. See: http://creativecommons.org/licenses/by-nc/4.0/.

ORCID iD

Lina Roa http://orcid.org/0000-0001-6552-4452

\section{REFERENCES}

1 Jha AK, Larizgoitia I, Audera-Lopez C, et al. The global burden of unsafe medical care: analytic modelling of observational studies. BMJ Qual Saf 2013;22:809-15.

2 Meara JG, Leather AJM, Hagander L, et al. Global surgery 2030: evidence and solutions for achieving health, welfare, and economic development. Lancet 2015;386:569-624.

3 Nepogodiev D, Martin J, Biccard B, et al. Global burden of postoperative death. Lancet 2019;393:401.

4 Institute of Medicine Committee on Quality of Health Care in, A., in Crossing the Quality Chasm: A New Health System for the 21st
Century.. National academies press (US). National Academy of sciences. Washington DC, 2001.

5 Donabedian A. The definition of quality and approaches to its management. Ann Arbor: Health Administration Press, 1980: 1. 163.

6 Donabedian A. The quality of care. How can it be assessed? JAMA 1988;260:1743-8.

7 Saluja S, Mukhopadhyay S, Amundson JR, et al. Quality of essential surgical care in low- and middle-income countries: a systematic review of the literature. Int J Qual Heal Care [Internet] 2018.

8 Agency for Healthcare Research and Quality. U.S. Department of Health \& Human Services [Internet]. Available: https:// qualityindicators.ahrq.gov [Accessed 2017 Apr 24].

9 American College of surgeons. National surgical quality improvement program (NSQIP, 2020.

10 Specifications Manual for Joint Comission National Quality Measures. The joint Comission, 2018. Available: https://www. jointcommission.org/specifications_manual_joint_commission_ national_quality_core_measures.aspx

11 The Hospital Value-Bassed Purchasing (VBP) Program. Centers for Medicare \& Medicaid Services [Internet]. Available: https://www.cms. gov/Medicare/Quality-Initiatives-Patient-Assessment-Instruments/ Value-Based-Programs/HVBP/Hospital-Value-Based-Purchasing. html

12 Citron I, Saluja S, Amundson J, et al. Surgical quality indicators in low-resource settings: a new evidence-based tool. Surgery 2018;164:946-52.

13 Scheffer M. Demografia MEDICA no Brasil. Sao Paulo: FMUSP, 2018: 286.

14 Massenburg BB, Saluja S, Jenny HE, et al. Assessing the Brazilian surgical system with six surgical indicators: a descriptive and modelling study. BMJ Glob Health 2017;2:e000226.

15 Scheffer MC, Guilloux AGA, Matijasevich A, et al. The state of the surgical workforce in Brazil. Surgery 2017;161:556-61.

16 Six Domains of Health Care Quality. Agency for Healthcare Research and Quality [Internet]. Available: https://www.ahrq.gov/talkingquality/ measures/six-domains.html

17 Tsai TC, Joynt KE, Orav EJ, et al. Variation in surgical-readmission rates and quality of hospital care. N Engl J Med 2013;369:1134-42.

18 Fischer C, Lingsma HF, Marang-van de Mheen PJ, et al. Is the readmission rate a valid quality indicator? A review of the evidence. PLoS One 2014;9:e112282.

19 Thaddeus S, Maine D. Too far to walk: maternal mortality in context. Soc Sci Med 1994;38:1091-110.

20 Anderson GA, Ilcisin L, Kayima P, et al. Out-Of-Pocket payment for surgery in Uganda: the rate of impoverishing and catastrophic expenditure at a government Hospital. PLoS One 2017;12:e0187293.

21 KoBo Toolbox. Harvard Humanitarian Initiative. [Internet]. Available: https://www.kobotoolbox.org

22 IBEG. Instituto Brasileiro de Geografia e Estadistica (IBGE) [Internet], 2020. Available: https://www.ibge.gov.br/

23 OECD. OECD Purchasing Power Parities (PPP) [Internet], 2018. Available: https://data.oecd.org/conversion/purchasing-powerparities-ppp.htm

24 HCAHPS. Hospital Consumer Assessment of Healthcare Providers and Systems [Internet], 2020. Available: https://www.hcahpsonline. org

25 Ribeiro TA, Premaor MO, Larangeira JA, et al. Predictors of hip fracture mortality at a general Hospital in South Brazil: an unacceptable surgical delay. Clinics 2014;69:253-8.

26 Vashistha N, Singhal D, Budhiraja S, et al. Outcomes of emergency laparotomy (EI) care protocol at tertiary care center from Low-MiddleIncome country (LMIC). World J Surg 2018;42:1278-84.

27 Motta Filho GdaR, Neves da Silva LdeF, Ferracini AM, et al. The who surgical safety checklist: knowledge and use by Brazilian orthopedists. Rev Bras Ortop 2013;48:554-62.

28 A percepçāo dos brasileiros sobre a saude e o SUS [Internet]. Conselho federal do medicina, 2013. Available: http://www.crmes. org.br/index.php?option=com_content\&view=article\&id=21208:apercepcao-dos-brasileiros-sobre-a-saude-e-o-sus\&catid=3:noticias \& Itemid $=462$ 